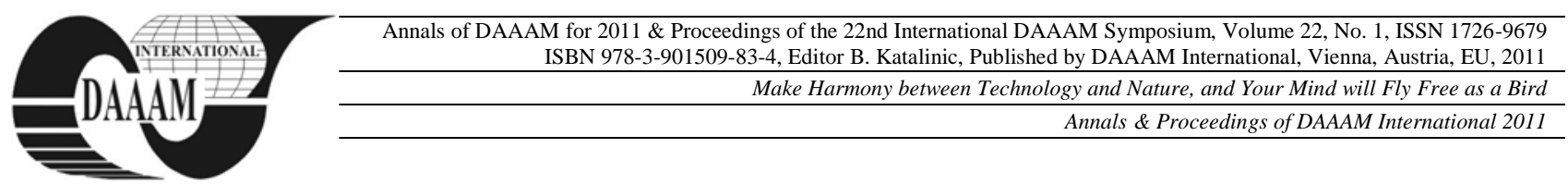

\title{
MATERIAL FLOW IMPROVEMENT IN AUTOMATED ASSEMBLY LINES USING LEAN LOGISTICS
}

\author{
BULEJ, V[ladimir]; STOIANOVICI, G[abriela] - V[eronica] \& POPPEOVA, V[iera]
}

\begin{abstract}
The main purpose of this paper is to focus on one of the more comprehensive current initiatives, those building on lean practices and principles, in the context of assembly lines processes, in order to build a deeper understanding how lean instruments can improve materials flows based on the interdependence of lean techniques. To deal with the question how to improve the materials flow in a lean environment, we have adopted a twofold approach in this article based on an analysis of existing literature on the subject and the observation of practices in the workplace. The observation of workplace practices make possible to compare different solutions advance by advocates of the lean approach with the facts. The views expressed in this regard will be based on the observation of companies from car assembly sector, which have implemented lean logistic for over four years.
\end{abstract}

Key words: assembly systems, lean logistics, pull, kanban

\section{INTRODUCTION}

Lean logistic is focused on keeping the minimum stocks needed to support production but monitor it closely, plan production to smooth the consumption rate of each item over time, organizing the inbound logistics to make replenishment lead times more predictable and respond with countermeasures at the first sign of problems.

In order to develop an assembly system, it is essential to consider all aspects of production system. Enhancing the capacity of production line without considering other requirements can result in the failure of a development plan.

One of the most important issues in the implementation of a development plan is the management of materials flow in the company (Coffey, 2006).

Material flow management refers to the planning and allocation of necessary resources to each production unit in the planned time schedule. In companies where production is carried out discretely and in separate units, transportation of intermediate products among different units of the assembly line is very important. Furthermore, when for different reasons, transportation among different units is done through various transportation modes. Complication of the management system rises while implementing the plan. Physical state of the materials and intermediate products, size and dimensions, combustibility, transfer rate, and other are conditions that gave rise to the simultaneous use of a variety of transportation modes or communicating among different units of a manufacturing company (Wagner \& Enzler, 2005).

The goal of materials flow management is to minimize the steps and stops that an item goes through on its movement to and from the shelves. It's about automating the materials flow process, eliminating unnecessary steps, and streamlining and speeding up steps, that can't be eliminated (Hwang, 2009).

For Making Materials Flow, the company must follow a five-step approach to create an improved system of material handling and material tracking.
- Developing the plan for every part (PFEP), a database to control inventory;

- Building the purchased-parts market, a central location to eliminate the waste of hoarding, searching for parts and storing inventory throughout a facility;

- Designing delivery routes, a system for getting the right parts to the fingertips of operators;

- Implementing pull signals, methods to keep inventory under control, and

- Periodic audits make sure the system keeps working.

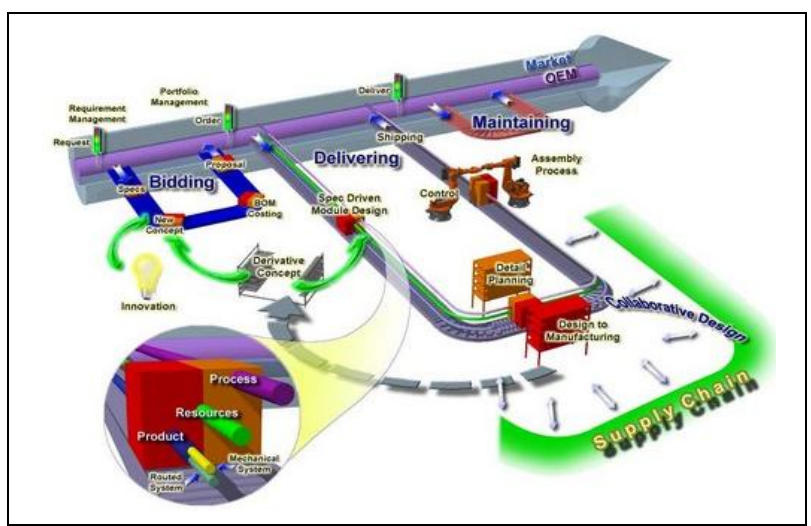

Fig. 1. Developed plan of company

\section{CASE STUDY OF MATERIALS FLOW IMPROVMENT IN LEAN ASSEMBLY SYSTEMS}

This study presents solutions and key elements for improvement of the materials flow, after the study of several assembly lines for automotive industry and different solutions and improvement steps resulted after analyzing the transportation network of raw materials, intermediate products, and final products.

In assembly lines where assembly processes are time consuming, regulation of materials flow and preparation of necessary materials for each stage of assembly is extremely essential. Even so, preventing the increase of unnecessary temporary stocks in the process of production and decreasing transportation activities play vital roles in reducing the assembly's indirect costs. The reason lies in the fact that transportation and storage are among activities that bring no added value for the system but add very high costs (Fig.2).

Using materials flow management and providing each stage with necessary materials is especially essential for these systems. Moreover, lack of a proper planning in transportation section, can create several obstacles in company's assembly systems and thus result in disruption of assembly process.

For observation of the transferring raw materials and final product into/from the system and flow of intermediate products in the system, the lean assembly system must have real time information about the following metrics: stocks of parts, stocks in intermediate warehouse, dock-to-dock time and lean rate. 


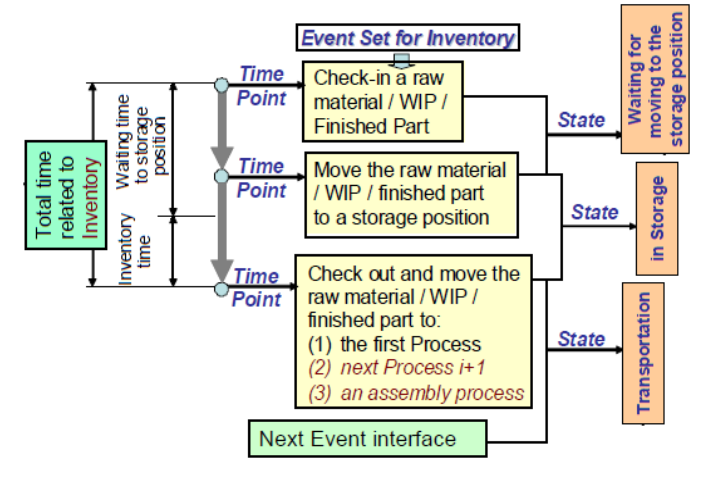

Fig. 2. The relation between inventory events and non adding value activities in materials flow

These are important to evaluate the situation because: Dock-to-dock time is the time the product spends from reception in plant to delivery or shipping, excluded the storage time and Lean rate (fig. 2) is the relation between value-added time and the time the product spends in the plant from when it enters until it leaves (Domingo, 2007).

One solution for an improved materials flow can be a reordering system, established across the production line to a fixed timetable and with a defined path, picking up any empty packages (or magazines), and supplying full packages to the same point. This system can be a transport system for the horizontal movement of materials, such as an automated guided vehicle, container or conveyor, appropriate to the needs of each production area and to the volume of parts to be transported. The adopted solution is not usually automation. In lean assembly plants, the current priority is to manage the manual part of the process. When the vehicle travels the path, if there are no parts to pick up or supply, then the vehicle continues on its programmed route.

This kind of supply system is called the milkrun, because it is a production system similar to that used in small supermarkets with a fixed amount of shelf space; the operator takes the necessary materials for production and stocks the empty packages after consumption. The supermarket's capacity must allow for materials availability between two consecutive runs, so that the operator does not stop working. In the milkrun path, the empty packages are withdrawn. They are not replaced until the following path of the milkrun, when it restocks the materials and withdraws any further empty packages that it finds. Therefore, the objective of the milkrun (helped by the kanban) is to integrate the internal supply of parts with the supply in the assembly area (Zhang \& Jiang, 2008).

One facility, for example is Creating Continuous Flow, that can take a dramatic leap to embrace lean production on a plantwide basis by creating high-performance assembly lines.

Other solution can be introducing a lean production-control system using kanban to connect a finished-parts market with the pacemaker and the pacemaker with a purchased-parts market near the receiving dock (Fig. 3).

The control system must provide some important Lean differentiators, including Mixed Model line levelling, advanced pull processes based on TPS, and coordinated machining and work centre groupings, but use Pacemakers to control the heartbeat of the factory.

Other solution can be introducing a lean material-handling system, this will make materials flow throughout the facility with much higher accuracy at much lower cost. For this a manufacturing company need:

- A process for describing with great precision how every part would be managed from the receiving dock to its point of use in the plant.

- A purchased-parts market near the receiving dock to hold and control the necessary parts.
- A precise delivery system to get the parts to the point of use.

- A precise signaling system that each production area would use to pull just the parts it needed from the purchased-parts market.

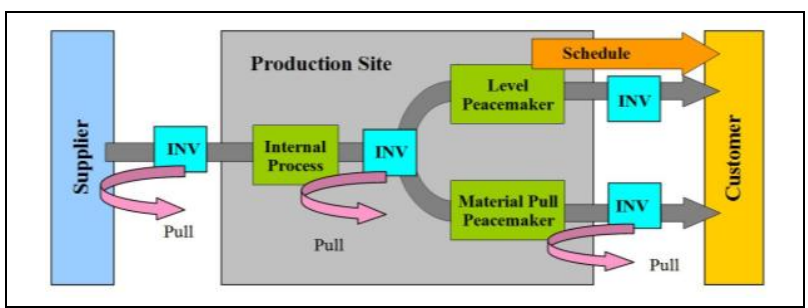

Fig. 3. Advanced pull processes based on Toyota Production System model

\section{CONCLUSIONS}

Influence of lean practices contributes substantially to the operating performance of plants. However, the implementation requires customized solutions. The internal materials flow to and from each workstation depend on the production conditions and particular characteristics of each workplace. The work-inprocess must be as reduced as much as possible. The immediate requirements are problems solution and a fluent flow, balance and synchronization, and a shorter cycle time. For this, routing flexibility is a key factor. Routing flexibility is defined as the ability to produce a part by alternative routes through the system. Design of the routing requires an evaluation of the entire loaded and unloaded handling system for a given shop layout for efficient materials flow. In lean manufacturing, materials handling systems must contribute to synchronous materials flow.

"Development of transportation network" and "increasing the number of vehicles for transferring of raw materials, intermediate and final products" (hardware solutions) is the first solution for solving the problem. This solution has very highs costs, however it may be possible to create some changes in the system units and thus improve system's productivity.

Next step is to simulate and evaluate the changing possibility in the system units (software solutions) and calculate the production time and productivity rate after the change.

\section{ACKNOWLEDGEMENT}

This article was made under the support of Grant Agency KEGA Slovak Republic - project No: 086-051 ZU-4/2010. The work has been partial funded by the Sectoral Operational Programme Human Resources Development 2007-2013 of the Romanian Ministry of Labour, Family and Social Protection through the Financial Agreement POSDRU/88/1.5/S/61178.

\section{REFERENCES}

Coffey, D., Thornley, C. (2006), Automotive Assembly: Automation, Motivation and Lean Production Reconsidered', The International Journal of Assembly Technology and Management, Vol 26, No 2, pp 98-103, ISSN: 1741-0386 173

Domingo, R., (2007) Materials flow improvement in a lean assembly line, Assembly Automation, Vol. 27, No. 2, pp.141-147, ISSN: 1741-0387

Hwang, H.S. (2009), Heuristic transporter routing model for manufacturing facility design, Computers \& Industrial Engineering, Vol. 46 No. 2, pp. 243-51, http:// dx.doi.o org/10.1016/j.cie.2003.12.021

Zhang, Y., Jiang P., (2008), RFID-based smart Kanban for JustIn-Time manufacturing, Int. Journal of Materials and Product Technology, Vol 33, No.1, pp 170-184

Wagner, B., Enzler, S. (2005). Material flow management: Improving cost efficiency and environmental performance. Heidelberg, Physica-Verlag, ISBN:3790815918 